\title{
RITOS DE INICIACIÓN EN LA NARRATIVA DE MICHEL TOURNIER
}

\author{
$M^{a}$ Eugenia Peñalva García
}

\begin{abstract}
Michel Tournier is above all a writer of myths. "Les Météores" and "Le Roi des Aulnes" are the texts analized in this article. The iniciation rites consist in radical changes in the religious and social status of the individual that participates in the rites. Paul and Abel, heroes of these tales, make initiatic trips with the idea of reaching a superior level. Both had endured a symbolic death, and are reborn later as fully superior inmortal beings. Abel, hero of "Le Roi des Aulnes", goes through a sries of initiation rites in the story. These rites help him to get ready to approach the end, which is the culmination of the initiation rites. When Abel died and was transformed by assimilation into the next "Roi des Aulnes". Being buried in mother earth is the price that the hero has to pay to achieve this return to his lost oneness, which is the only way to acquire inmortality. Paul on the other hand will harmonize the different elements of the text through the three steps of the initiatic journey. Paul resucitates symbolically and becomes a meteor. As he becomes part of the cosmos he is transformed into an aerial being. It can be said that Torunier is a writer who tries to renew some obsolete literary genres, such as the epic, allegory, and spiritual genres.
\end{abstract}

Michel Tournier es ante todo un escritor de mitos. Los relatos que analizamos en este trabajo, "Le Roi des Aulnes" y "Les Météores", fueron escogidos precisamente por su alto contenido mítico, y porque los héroes principales realizan viajes iniciáticos que los conducen por dificilísimos caminos cuyo fin es la inmortalidad. Hablemos un poco sobre lo que se entiende por ritos iniciáticos.

En general todos los antropólogos coinciden en que el esquema habitual de la iniciación es el acceso del ser humano a un plano superior de conocimientos y de sensibilidad, que asegure el paso de lo profano a lo sagrado y que este paso debe reposar sobre un drama, el cual es comparable a toda creación. Por ello, el aspirante debe morir simbólicamente, para poder renacer, para poder acceder a una transfiguración. ${ }^{1}$

Según Gilbert Durand, todas las ceremonias iniciáticas que son liturgias o repeticiones del drama temporal y sagrado, del tiempo dominado por el ritmo de la repetición, son isomorfas a ese mito sagrado y cíclico del Hijo.

Para Mircea Eliade la iniciación es un conjunto de ritos y de enseñanzas orales al que sigue la modificación radical del estatus religioso y social del sujeto que realiza la iniciación. Al final de sus pruebas el iniciado goza de una existencia diferente a la de antes porque se ha transformado en otra persona. La iniciación introduce al neófito, al mismo tiempo, en la

${ }^{1}$ Aziza, Claude; Olivieri, Claude y Sctrick, Robert. Dictionnaire des symboles et des thèmes littéraires, Ed.Fernand Nathan, 1978. p.120. 
comunidad humana y en el mundo de los valores espirituales. Por lo que el iniciado aprende sobre todo las relaciones místicas entre la tribu y los Seres sobrenaturales. No se puede comenzar una iniciación sin antes haber preparado espiritualmente al iniciado. ${ }^{2}$

El momento central de toda iniciación es representado por la ceremonia que simboliza la muerte del neófito y su regreso entre los vivos. Pero el que regresa es un hombre nuevo con una nueva manera de ser. La muerte iniciática significa a la vez el final de la infancia, de la ignoracia y de la condición profana. ${ }^{3}$

En el escenario de los ritos iniciáticos la muerte corresponde al retorno provisional del caos, es la expresión ejemplar del final de un modo de ser: el de la ignorancia y de la irresponsabilidad infantil. ${ }^{4}$

Todos los ritos de renacimiento o de resurrección y los símbolos que implican, indican que el iniciado ha accedido a otro modo de existencia el cual es inaccesible a todos los que no han afrontado aún las pruebas iniciáticas, es decir que no han conocido la muerte.

Así pues, la muerte iniciática es indispensable para el comienzo de una vida espiritual. Su función se debe comprender en relación con el nacimiento de un ser superior. Muchas veces la muerte iniciática se simboliza por las tinieblas, por la noche cósmica, por la matriz telúrica, la cabaña, el vientre de un monstruo, etc. ${ }^{5}$

En los libros analizados, Tournier ha seguido paso a paso todos los ritos necesarios en una iniciación. Sus héroes se han visto preparados desde el principio, luego han ido sufriendo una serie de pruebas hasta llegar a la muerte simbólica, para renacer más tarde, convertidos en verdaderos seres superiores e inmortales. De hecho se les puede llamar héroes porque precisamente logran encontrar un remedio a todas las situaciones míticas. Esta solución puede ser una salida positiva o negativa.

El primer relato, es decir "Le Roi des Aulnes", es la historia de Abel Tiffauges, propietario de un taller parisino, asediado por los signos. Redacta un diario al que llama siniestro porque lo escribe con la mano izquierda. aunque también lo considera siniestro, en el sentido figurado de la palabra, es decir, como algo malo o perverso. Estos "écrits sinistres", que constituyen un tercio del conjunto del texto, cuentan la historia de su niñez en una institución religiosa: el colegio "Saint Christophe."

Es una infancia triste. Abel es un niño débil y sensible por lo que es humillado por los más fuertes del colegio. En la escuela conoce a Nestor, un chico cuya "masa formidable" fascina a Abel, convirtiéndose así en su mentor iniciático. De éste heredará su naturaleza ogresca y su amor por la "phorie", así como también la miopía.

El diario se desarrolla desde el 3 de enero de 1938 hasta el 4 de septiembre de 1939. En él Abel cuenta todas sus obsesiones y sus pasiones.

\footnotetext{
${ }^{2}$ Eliade, Mircea. Iniciation, rites, sociétés secrètes, p.12.

${ }^{3}$ Ibidem, p. 16 .

${ }^{4}$ Ibidem, p.17.

${ }^{5}$ Ibidem, p.18.

${ }^{6}$ Michel Toumier entiende por este termino el acto de transportar a algun ser vivo sobre sus hombros.
} 
Acusado de una violación, que de hecho no ha cometido, Abel Tiffauges se enfrenta nuevamente a los signos, que según él hacen cambiar la Historia. En 1939 comienza la Segunda Guerra Mundial y él es enviado como soldado colombófilo a Estrasburgo. Abel es hecho prisionero y transportado a Alemania, lugar en el cual tendrá lugar el resto del relato.

El amor por los niños es momentáneamente desviado hacia los animales; primero serán las palomas, luego los ciervos y después los caballos. Acepta encantado su movilización y el comienzo de la guerra, pues para él es el castigo de una sociedad que tiene un orden injusto y criminal, en la cual ha sufrido mucho. Soporta su prisión con serenidad, incluso con felicidad. En el campo de prisioneros aprende a amar la tierra prusiana y poco a poco se va identificando con el pueblo alemán. La tierra se convertirá para él en un lugar mítico y de ensueño, en donde todo será posible. El guardia forestal de la reserva de Rominten lo descubre en la cabaña del bosque, a la que Abel llamaba "Canadá" y le propone trabajar para él como hombre de confianza.

Al llegar a la reserva, Abel se enfrenta por primera vez a un entorno hecho enteramente a su medida, conoce al ogro Göring y se identifica plenamente con él. Aquí, definitivamente se olvida de su condición de francés y se germaniza. Se encuentra en pleno corazón del país alemán, en la región donde Hitler ha establecido su cuartel general. De momento no se da cuenta de cómo son los nazis. Por casualidad está presente en la exhumación de un cadáver germano extraído de las turberas y al que llaman "Roi des Aulnes". Abel va a tomar posesión de esta tierra prusiana, convirtiéndose en su amo. Su misión es la de conseguir niños de raza aria pura. Recorre la región a lomos de su caballo Barba-Azul y provee niños para el gran ogro Hitler y su máquina de matar: la guerra. Entonces se metamorfosea en el "Rey de los Alisos", convirtiéndose en el ogro que mata a los niños.

El relato termina con la derrota nazi. Abel encuentra a un niño judío, Ephraïm, escapado de Auschwitz, con una estrella de David en el brazo. Lo transporta a la Napola, efectuando de esta manera su primera "astrophorie." ${ }^{8}$ Gracias a él se entera de lo que es el aparato nazi: comprende que los campos de concentración son la inversión maligna de su ciudad fórica. Se escapa de la Napola, con Ephraïm a hombros, justo en el momento en que ésta está siendo atacada por los rusos. Logra salir de ella y se dirige al bosque cenagoso de alisos negros, donde se hunde inexorablemente, uniéndose de esta manera con la tierra prusiana y convirtiéndose en el nuevo "Roi des Aulnes". Ephraïm se metamorfosea en estrella, volviéndose, también inmortal.

Abel es enviado a realizar una misión muy difícil durante su viaje iniciático: encontrar su unidad perdida en el principio de los tiempos. Tournier le disemina, a lo largo de su camino, miles de pruebas que deberá afrontar y superar para poder seguir adelante con su hazaña. Estas pruebas son las iniciaciones a las que se verá enfrentado y que lo conducirán al encuentro de esa unidad perdida de los orígenes.

Toda iniciación tiene que pasar por tres etapas esenciales:

\footnotetext{
${ }^{7}$ Poema de Goethe, que da su título al libro.

${ }^{8}$ Por "astrophorie" Tournier entiende la acción de cargar, metafóricamente, a un astro, hecho que sucede cuando Abel toma en sus brazos a Ephraïm.
} 
En primer lugar la preparación, que consiste en algún sufrimiento: ayuno, soledad, abstinencia, con el fin de romper de alguna manera con el mundo de los vivos. Luego la iniciación en sí, que no es más que una muerte simbólica. Una muerte que significará un viaje al más allá. Este viaje otorga al iniciado un retorno a la vida embrionaria, que le ayudará a abordar una vida llena de promesas nuevas. Esta muerte simbólica le permitirá renacer con mucho más ímpetu. Durante esta fase el iniciado lucha internamente contra los seres infernales, contra el mal que hay dentro de él.

Y por último, la tercera etapa es aquélla en la que el iniciado resucita. Esta resurrección simbólica es de orden espiritual y, gracias a ella, el iniciado se adhiere a la comunidad humana en la que desea ser aceptado.

La iniciación es pues un sufrimiento que permite al hombre acceder a un modo de vida superior, mediante un retorno a sus orígenes.

En el relato, la vida entera de Abel Tiffauges se ve confrontada con la iniciación, en suma no es más que un viaje iniciático. Es la trayectoria existencial del héroe, primero en el colegio y luego durante su viaje a Prusia Oriental.

Su primer sacerdote iniciático es Nestor. Abel se siente rechazado por sus padres y a su vez él los rechaza y se considera un ser solitario. Por lo que, falto de cariño, se siente atraído por Nestor, personaje sumamente interesante y lleno de poder dentro de la escuela. La posesión del giroscopio le confiere un carácter mágico. Es Nestor quien adopta a Abel y lo inicia en sus múltiples ritos. Primero, con el giroscopio, le permite conocer la gravitación terrestre y las sensaciones cósmicas.

Luego le transmite su fascinación por el libro "Le Piège D'Or" de Curwood y le hace descubrir el amor por las tierras simbólicas. Hereda también de él su pasión por la coprología y su amor fórico.

La muerte de Nestor no fue una muerte simbólica sino real, pero renace en Abel. Es como si hubiese sufrido una metamorfosis. Por lo que el héroe que es pequeño y enclenque, adquiere de repente un amor loco por la comida cruda, crece y se convierte en un gigante. Además se vuelve miope, esta enfermedad le permitirá ser un visionario que adivina el futuro a través de los signos. Todos estos signos son la herencia de Nestor.

La preparación de Abel en el colegio para la muerte simbólica, que le permitirá acceder al mundo de Nestor, es toda la etapa que pasa siendo esclavo de Pelsenaire. Este sufrimiento lo va preparando para poder entrar al mundo mágico que le ofrece Nestor. La muerte simbólica en sí, es el momento culminante en que debe sufrir el castigo "ad colaphum".

Esta muerte simbólica le permite el renacimiento, que implica para Abel la iniciación que le proporciona Nestor.

"J'étais loin de soupçonner que je venais d'assister à la formation d'une première fissure dans le bloc monolithique du destin qui m'écrasait. Dès ce jour mémorable, j'aurais pu cesser de le considérer comme un enchaînement inéluctable et a priori hostile, et reconnaître -comme j'y ai été contraint depuis- qu'il pouvait entretenir une certaine complicité avec ma petite histoire personnelle, et en somme qu'il pouvait entrer du Tiffauges dans le cours des choses." (pp. 49-50) 
Este es el primer grado de iniciación en la vida de Abel, el cual le permite ir incubando todos los granos que le servirán para su segunda iniciación. Esta se presenta cuando Raquel rompe con él, hiriéndolo profundamente en su amor propio.

"Ce jour-là elle observa négligemment en se rhabillant que je faisais l'amour comme un serin... Comme un serin... Depuis six mois que cette parole fut prononcée, elle a longuement, profondément cheminé en moi." (pp. 20-21)

Este sufrimiento es la preparación para la muerte simbólica, que será el momento en que por fin descubra su primer éxtasis fórico.

"C'est alors que quelque chose a fondu sur moi, d'une intolérable et déchirante douceur. J'étais sidéré par une foudroyante bénédiction tombée du ciel." (p.13)

Así logra renacer en un nuevo mundo en el cual Abel se consagra a la fotografía de niños. Para él es una forma de posesión simbólica. Esto le prepara para su tercera y última iniciación que será la más importante de todas dentro de su viaje iniciático.

Cuando Abel es acusado de violación comienza la preparación para esta iniciación en tercer grado. En esta prueba Abel es humillado, le escupen a la cara, lo rebajan de su rango de ogro fórico. Pero gracias a esta prueba logra partir a Prusia Oriental, momento en que por fin su destino empieza a perfilarse.

Observamos que la guerra es una ruptura liberadora para él ya que da pie a su viaje iniciático, que es rumbo al este, como todos los viajes iniciáticos de los cuentos. Entonces llega una nueva prueba para Abel: es hecho prisionero. Su vida de soldado colombófilo no había sido más que un paréntesis antes de llegar a esa muerte simbólica. Esta se le presenta cuando en su cautiverio se siente profundamente atraído por la tierra prusiana, perdiendo así su identidad como francés.

Descubre una cabaña a la que llama "Canadá" y lo relaciona con la historia de Curwood. De esa manera, cuando asiste a la exhumación del cadáver del germano, tiene ya un motivo de identificación con él: el amor por esa tierra negra, además de ser el elemento femenino que le falta para encontrar su unidad.

Es su cautividad, vista como muerte simbólica, la que le permite acceder a su florecimiento como ogro fórico en la Napola de Kaltenborn. Este es el renacimiento apoteósico de Abel, que llega a su máxima culminación cuando Abel sufre el bautizo de sangre.

"Un manteau de pourpre a pesé d'un poids intolérable sur mes épaules, attestant ma dignité de Roi de Aulnes. Et ce manteau était Arnim le Souabe." (p. 545)

Es así como Abel llega al máximo grado de iniciación en su calidad de ogro. Es en Kaltenborn donde logra la total felicidad a través de su momento utópico y se convierte en ogro triunfante, pero sólo transitoriamente.

El final del relato es la culminación del rito de iniciación. Cuando Abel muere y se transforma por asimilación en el próximo "Roi des Aulnes" en su aspecto positivo, sufre una muerte iniciática y se convierte en el nuevo mito germano. Normalmente la muerte iniciática es siempre una muerte simbólica, que se convierte en rito de pasaje hacia la inmortalidad, que no es otra cosa que un modo de vida superior. Sin embargo, Abel sufre una verdadera muerte 
física, el autor ha querido que este héroe renazca simbólicamente al convertirse en ser inmortal, cuando asume el papel de "Roi des Aulnes". Ephraïm de liberado, se convierte en liberador, de ahí su metamorfosis en estrella. Se logra pues un final apoteósico. La muerte adquiere por tanto un valor iniciático de rito de paso hacia algo superior.

"Les Météores" es la historia paralela de Alexandre Surin y de los gemelos Jean y Paul, narrada a lo largo de unos treinta años. Alexandre es el tío homosexual de Paul y Jean. Durante todo el relato se dedica a buscar su gemelaridad perdida, mientras que los gemelos, o mejor dicho Jean, se aplica en disolver, precisamente, esa unión gemelar que le atormenta.

El relato empieza contando la infancia de los gemelos en un pueblo de Bretaña. Paul desea vivir siempre dentro de la célula gemelar. Ama todo lo que es regular como, por ejemplo, los relojes, la astrología, el tiempo cíclico y cronológico. No le gustan las sorpresas, ni lo desconocido. Su gemelo Jean tendrá justamente el carácter opuesto. Ama todo lo irregular, como puede ser el tiempo meteorológico. Le gustan los cambios, la gente singular, y sobre todo, no desea vivir dentro del óvulo gemelar.

Cuando Jean llega a la edad adulta hace todo lo posible por separarse del yugo de Paul. El primer paso es su noviazgo con Sophie. Cuando Paul la conoce, intenta por todos los medios separarlos. Sophie huye y Jean decide romper definitivamente con su gemelo, emprendiendo un viaje alrededor del mundo.

Al enterarse Paul, inicia la persecución de su gemelo a través de Venecia, Túnez, Islandia, Japón, Canadá y Berlín. Este será el viaje iniciático, donde se preparará para su metamorfosis final en un ser cósmico. Durante este viaje, Paul aprenderá a conocer el espacio y a captar la diferencia entre el tiempo cronológico y el tiempo meteorológico. Aprende a vivir sin su gemelo, llegando a la conclusión de que no lo necesita.

En Berlín sufre el rito de iniciación final que consistirá en la mutilación de su flanco izquierdo. Una vez obtenida la muerte simbólica, Paul resucita convertido en un meteoro, logrando de esta manera integrarse en el cosmos. Paul pierde a su gemelo, sin embargo Jean regresa a formar parte del flanco mutilado de su hermano. Paul se transforma finalmente en un ser cósmico, logrando definitivamente lo que tanto anhelaba: convertirse junto con su gemelo en un único ser unido a través de la meteorología.

Alexandre por su parte es el héroe que desea encontrar desesperadamente una pareja afín a él, sin nunca llegar a encontrarla.

Cuando muere el hermano mayor, la familia le obliga a hacerse cargo del negocio de regeneración de basura. Para su gran asombro, Alexandre descubre que este tipo de trabajo le complace, identificándose plenamente con él. De esta manera se convierte en el "Dandy des Gadoues".

En este medio tan hostil y atractivo al mismo tiempo, Alexandre se dedica a buscar a su gran amor, sin darse cuenta de que en realidad lo que quiere encontrar es a su gemelo perdido. Cuando logra captar la profundidad de sus sentimientos, y una vez que Dani, su amor platónico, ha sido asesinado por las ratas, Alexandre se deja llevar hasta los muelles de Casablanca, donde lo asesinan otros dos homosexuales a los cuales él a su vez da muerte. 
Este relato no es otra cosa mas que el análisis del mito de la gemelaridad visto desde dos ángulos diferentes. Por una parte se nos muestra la vida de dos auténticos gemelos y por otra parte el autor describe la historia de un "singular" cuyo deseo primordial es encontrar a ese gemelo perdido.

En "Les Météores" el que sufre la iniciación es Paul, pero quien la provoca es Jean, pues es él quien escapa de la célula gemelar. Este desaparece como un fantasma, dejando tras de sí sólo algunas huellas.

Entonces Paul, en tanto que iniciado, tiene que ir imaginando la ruta que le va señalando Jean el iniciador. En un principio, Paul no entiende la decisión de su hermano, tiene que interpretar cada uno de los movimientos de Jean y analizarlos. Pero poco a poco, va comprendiendo las pautas que le va marcando su gemelo.

El primer paso dentro de la iniciación, es decir, la preparación del iniciado, consiste en el viaje que Paul realiza a través del mundo en busca de su hermano. Como ya hemos dicho, este primer paso va unido a un sufrimiento por parte del iniciado. En este caso, el dolor no es físico sino emocional. Paul sufre enormemente por la ausencia de su gemelo, padece una terrible soledad, la cual no le abandonará hasta que llegue a la tercera fase de la iniciación.

El viaje comienza hacia el sureste, desde Bretaña a Venecia y de allí, aún más al sur, a la isla de Djerba, en Túnez. En este momento Jean decide cambiar de rumbo hacia el norte, pasando por Islandia, antes de encaminarse de nuevo hacia el este, para llegar al Japón. Siempre hacia el este, se dirige al Canadá, llegando a Vancouver. Desde ahí recorrerá el país de oeste a este llegando a Montreal. Su última etapa será Berlín, por lo que, de nuevo, continúa hacia el levante.

Observamos que todo su viaje, salvo la etapa de Islandia, lo realiza siguiendo casi una línea recta hacia el este. Ya hemos visto que Abel realiza su periplo iniciático también rumbo al este. Para Tournier esto no es una casualidad, está convencido de que todos los viajes inciáticos de los cuentos se llevan a cabo en esta dirección.

La primera etapa es Venecia. Aquí tendrá que enfrentarse a los espejos venecianos. Conocerá al meteorólogo gracias al cuál comenzará a comprender mejor el tiempo cósmico. Son los primeros pasos dentro de su iniciación.

Pero también se sentirá profundamente solo, perdido como en un laberinto. Es curioso notar que la primera ciudad visitada es una ciudad gemelar, parece como si el iniciador quisiera hacer un poco más fácil esa dura prueba para la que se prepara Paul. Constatamos que el iniciado sufre enormemente, sobre todo por la ausencia de su hermano gemelo, aún no puede superar esa dura soledad. Además, es consciente de que está en una ciudad muerta, donde no hay estaciones y cuyos habitantes se ven continuamente amenazados por el agua.

Esta primera etapa está llena de símbolos. Cuando llega a la ciudad lo reciben palomas volando junto al barco a las que Paul compara con la paloma del Arca de Noé. Encuentra a personajes que creen estar viendo a Jean.

Así pues, en este primer lugar, Paul comprende que va por buen camino para encontrar a su hermano. Acepta su sufrimiento y decide seguir a Jean a través de las pistas que le va dejando. 
De esta manera llega a Túnez, a la isla de "Lotophages". Ya el nombre mismo nos evoca algún lugar mítico. Esta isla es igualmente mágica e idílica. Aquí corre el riesgo de olvidar por qué está allí. Se siente tan feliz junto a Ralph y Deborah que le gustaría quedarse. Pero la muerte de Deborah lo vuelve a la realidad y se da cuenta de que tiene que continuar su camino.

En esta segunda etapa de su viaje, Paul comienza a sentir a Jean dentro de sí mismo, ya no sufre tanto de la soledad como en Venecia y ya no tiene una necesidad tan acuciante de perseguirlo. Empieza a apropiarse de su gemelo.

Paul comienza a cambiar, el viaje lo encamina, a través del sufrimiento, hacia el segundo paso iniciático. Poco a poco empieza a comprender que su viaje no tiene como único objetivo el encontrar a su gemelo.

En Islandia, sigue buscando a Jean. En esta isla halla de nuevo el saludo de bienvenida de los pájaros. Todos estos símbolos le van mostrando el camino. Paul piensa que la gaviota es una mensajera simbólica, que viene a indicarle que el camino que sigue es el correcto. Siente que es una enviada del Dios del cielo, que le anticipa su destino final.

La siguiente etapa es el Japón. Aquí va a estar en contacto con la naturaleza en miniatura, típica de este país. Aprende la filosofía del Yin y del Yang. Gracias a estas enseñanzas empieza a comprender a su hermano gemelo, ya que, a través de los jardines miniatura se da cuenta de lo que significa la intimidad. En este país superpoblado, los habitantes deben de distanciarse los unos de los otros para poder sobrevivir. Eso lo logran a través de sus jardines.

A través de la filosofía del jardín Zen el cual lleva directamente al jardín-miniatura, Paul comprende finalmente lo que buscaba con tanto ahínco su hermano Jean. Ese deseo de independencia, ese anhelo por conocer todo lo perteneciente al mundo exterior.

Lo que Paul llega a discernir en el Japón es la conciliación entre su hermano y él. Por un lado entiende el deseo de cambio perpetuo que impulsa continuamente a Jean. Pero prefiere su manera de ser que lo estimula siempre a un sedentarismo por naturaleza estático y sin movimiento.

Pero esto no lo comprende de inmediato, del Japón sólo lleva el germen que le servirá en la tercera fase de la iniciación. Tiene que pasar todavía por Canadá y Berlín y sufrir la muerte simbólica para poder aprovechar todas las enseñanzas sembradas en su interior a lo largo del viaje iniciático.

Después de esta etapa su soledad empieza a disminuir. Interiormente sigue apropiándose de su gemelo, por lo que ya le es prácticamente indiferente encontrarlo, pues siente que puede incluirlo dentro de sí.

En el tren se cruza con su hermano y su reacción es contraria a lo que él siempre había imaginado. "J'ai peur (...) Peur de quoi? De la survenue de Jean! Suis-je devenu fou?" (p.566). Jean también lo percibe y se esconde. Cuando Paul constata que su hermano ha estado en el tren y que ha escapado sin verlo, no logra entender sus propios sentimientos.

Por primera vez dentro de esta fase inicial de la iniciación, no va en pos de su hermano, es decir detrás del iniciador. En este momento, el iniciado camina solo, pues sabe cual es la ruta a seguir y que lo conducirá a la segunda fase. 
En Berlín, Paul se enfrenta a los últimos rituales antes de pasar a la segunda etapa de la iniciación. Estos comienzan al mismo tiempo que la construcción del muro, con la clausura de las ventanas y el bloqueo de la entrada al edificio donde se encuentra con Frau Krauss. Comprenden que están encerrados, sin luz y sin la posibilidad de salir. Esto significa la ruptura definitiva con el mundo exterior, con el mundo profano que no está preparado para asistir al segundo rito de iniciación.

Después del encierro, vienen las ceremonias preparatorias del sacrificio. Durante este tiempo de oscuridad, Paul comienza a angustiarse. La primera ceremonia consiste en la celebración, un viernes, de una misa subterránea. Los asistentes a dicha ceremonia se asemejan a los primeros cristianos encerrados en las catacumbas. Dicha misa acerca a Paul a la edad mítica del comienzo de los tiempos.

La segunda ceremonia a la que asiste es la celebración de la Navidad en pleno verano. Frau Krauss, quien representa el papel de la sacerdotisa que lleva a Paul al lugar del rito inciatico, vive estos momentos como si fuesen sagrados, está muy excitada y exaltada e intenta transmitir al gemelo su alegría.

La sacerdotisa Krauss se encarga de preparar a Paul en estos últimos momentos antes de acceder al segundo estadio de la iniciación. El iniciado comienza a vislumbrar cambios en su porvenir.

Paul llega a la capital alemana con èl convencimiento de que todos esos kilómetros recorridos no son más que una parodia preparatoria para llegar a la ciudad clave que es Berlín y donde sufrirá su metamorfosis definitiva.

Paul, al igual que Abel, se verá enfrentado a las fauces de la tierra para poder acceder a esa muerte simbólica. En el caso de Paul el fallecimiento es únicamente simbólico, mientras que Abel, como ya vimos, muere efectivamente. Así pues el segundo paso de su iniciación es un descenso a los infiernos que le permitirá después la ascensión aérea. La iniciación en sí misma consiste en atravesar, arrastrándose por un túnel de lodo rojo, un paso. subterráneo que va de Berlín-Este a Berlín-Oeste. El pasadizo está muy mal apuntalado y cuando Paul lo cruza le caen encima toda una serie de tubos, gatos de coche y vigas de madera que destrozan parte de su cuerpo.

Este ritual del paso por la tierra roja se parece al que sufre Abel con el bautizo de sangre de "Arnim le Souabe". Lo que sucede después es lo que diferencia ambas iniciaciones. Abel muere, sin embargo obtiene la inmortalidad al convertirse en el nuevo "Rey de los Alisos". Se metamorfosea en un ser telúrico. Paul, en cambio, se convierte en un ser cósmico y aéreo, pero en vida. Su muerte es tan sólo simbólica.

La prueba de iniciación toma el carácter por lo tanto de un descenso a los infiernos. Se penetra en el dominio de la muerte, de la diosa de la obscuridad y de la noche, con el fin de acceder, o bien a la muerte misma, o bien a una nueva vida simbolizada en una ascensión aérea. Paul interpreta el accidente como la agresión de la "Madre Tierra" bajo la forma de una bruja con dientes mordicantes.

Por consiguiente, para poder alcanzar el tercer estadio de la iniciación, es decir, la resurrección simbólica, la prueba iniciática tiene que ser extremadamente difícil. Sin embargo, 
aquél que logra superarla, adquiere un inmenso poder que le otorga una superioridad sobre los no iniciados. Esta superación le confiere una naturaleza sobrehumana perdiendo totalmente el miedo a la muerte verdadera.

La prueba a la que se enfrenta Paul es la que está reservada a los héroes, la más difícil, la más trascendental. Comprobamos que el dolor de Paul es insoportable, pero gracias a él podrá acceder al último estadio de la iniciación. Compara su tortura "à un fauve invisible qui me déchire (...) et me mord" (p.606) Todo iniciado se ve obligado a soportar cierto grado de dolor, sin el cual no es apto para pasar a la siguiente prueba. Paul se obliga por ello a "affonter nu et seul, sans le bouclier anesthésique, la ruée de la souffrance. Apprendre à nager dans la souffrance." (p.607)

En todas las iniciaciones el dolor tiene un carácter ritual. Su objetivo es darle al iniciado más poder y transmitirle un valor espiritual a través del sufrimiento. Paul comprende finalmente que debe asumir ese dolor si quiere acceder a la etapa final, es decir a la ascensión a los cielos.

Su sufrimiento incluye también la pérdida del gemelo perdido "et la disparition inexplicable de Jean n'était que l'autre face de ce sacrifice." (p.618)

El primer paso de su transformación lo alcanza una noche hacia las tres de la madrugada. Es el premio a tanto dolor. Al superar esta dura prueba finalmente accede a la resurrección simbólica. "Je suis l'enfant qui vient de naître" (p.609). Por fin obtiene su premio, su recompensa. La parte de su cuerpo que ha sido amputada no está muerta, ha sufrido una transformación en organismo celeste y aéreo.

La tercera etapa de la iniciación corresponde pues a la resurrección simbólica, una vez que ha sufrido la muerte iniciática. Le cuesta mucho trabajo comprender todas las enseñanzas que ha ido adquiriendo durante la larga iniciación. Pero finalmente logra asociar todos sus conocimientos y todas sus experiencias en la superación de esta última fase.

"Je suis dans une bulle -plus ou moins gonflée. Je suis cette bulle. Tantôt sa membrane flasque, dégonflée se colle à mon corps, coïncide avec ma peau, tantôt elle déborde, elle englobe le lit, elle envahit la chambre." (p.606)

A través de esta "bulle", Paul alcanza la resurrección. Poco a poco va sintiendo cómo en sus muñones comienza a fluir la vida.

"J'ai senti très distinctement que quelque chose remuait dans mes deux pansements. Un gros insecte dans le pansement de mon bras, une petite souris dans celui de ma jambe." (p.611)

También va comprendiendo que esos pequeños animales que siente en sus llagas "obéissaient aux injonctions de ma volonté." (p.611)

Esos órganos móviles van adquiriendo autonomía con el tiempo. Comprende finalmente las enseñanzas aprendidas en el Japón y que le habían resultado entonces tan enigmáticas.

Su metamorfosis final en meteoro se realiza de manera gradual. Primero se convierte en árbol, ser vivo que participa al mismo tiempo de una naturaleza telúrica, gracias a sus raíces y de otra aérea, por sus ramas. 
Paul, como el árbol, que nace en la intimidad de la tierra, tiene que pasar primero por un estadio telúrico antes de acceder al estadio aéreo. En un principio no logra dominar el brazo y la pierna a la vez, cuando el brazo sale de excursión, la pierna no se mueve y viceversa. Sus paseos son siempre a ras de la tierra, visita las flores, los champiñones del suelo, etc. pero aún no tienen el poder de elevarse a las alturas.

Cuando logra dominar la pierna y el brazo izquierdos, comprende finalmente que tienen el poder de moverse por el mundo, porque son su hermano gemelo, quien finalmente, se ha unido a él.

"Ce corps gauche qui remue qui s'agite, qui pousse des prolongements fabuleux dans ma chambre, dans le jardin, bientôt peut-être sur la mer et au ciel, je le reconnais,c'est Jean incorporé désormais à son frère-pareil, Jean-le-Fuyard, Jean-le-Nomade, Jean-le-Voyageurinvétéré." (p.618)

Por último, asimila el tiempo meteorológico al cosmológico, se convierte en meteoro, es decir, pasa a formar parte del cosmos, se transforma en ser aéreo.

Su poder cósmico le sirve para desahogar sus penas en sus paseos por el espacio. Paul se ha transformado en Jean-Paul y ha encontrado finalmente la paz. Gracias a su mertamorfosis en ser cósmico entra en comunicación directa con el universo, pasa a formar parte de él, de la paz y de la armonía originales: "Tout est signe, dialogue, conciliabule. Le ciel, la terre, la mer se parlent entre eux et poursuivent leur monologue.” (p.623)

Como todos los demás héroes de Tournier, Paul reconoce el poder ilimitado que ha adquirido gracias a las tres etapas de la inciación. Es consciente de que ha sido doloroso, pero está convencido de que ha valido la pena. $\mathrm{Al}$ igual que $\mathrm{Abel}$ al introducirse en las turberas, ha encontrado la inmortalidad a través de su cuerpo volátil. Gracias a él ha conquistado la unidad gemelar, la ubicuidad y la eternidad.

\section{CONCLUSIONES}

Ambas novelas, que podríamos calificar de míticas, están llenas de simbolismo, el cual nos transporta como lectores, hacia ese mundo mágico que el autor desea hacernos conocer.

En "Le Roi des Aulnes", Abel, comprende a través de su itinerario que sólo puede lograr la transformación en hombre andrógino a través de su condición de ogro fórico y materno, que da lugar a la creación de una utopía que subvierte completamente la realidad histórica. Éste consigue encontrar, gracias a los niños, la clave de su ser, su propia esencia. Al volverse ogro materno, se vuelve también niño, recuperando así la estructura tríptica que añora.

El hundimiento en la madre tierra es el precio que tiene que pagar el héroe para lograr ese retorno hacia su unidad perdida, siendo la única forma de alcanzar la inmortalidad.

El héroe de este texto, al igual que todos los héroes de Tournier, es enviado a hacer un viaje iniciático cuya misión es la de encontrar su unidad perdida en el principio de los tiempos. Gracias a las iniciaciones que sufre puede alcanzar su condición de ogro, que le permitirá vivir una máxima felicidad a través de su momento utópico, en donde el tiempo permanece estático. 
La inclusión del héroe en el espacio de la intemporalidad hace de él un superhombre, es decir, lo eleva por encima de la humanidad para convertirlo en inmortal.

En "Les Météores" todos los héroes del relato, ansían reconciliarse con su propio yo. De ahí la obsesión de Tournier por idealizar siempre el mundo de los orígenes. Es en la materia original y aún pura donde el autor sueña con encontrar al ser autónomo, la célula perfecta y cerrada, el ser primitivo de los orígenes.

Alexandre es presentado como un personaje andrógino que se maneja entre el mundo gemelar y el mundo de los "sans pareil."

Tournier le adjudica una personalidad con tres aspectos distintos dentro de su mismo carácter: uno femenino, uno masculino y otro infantil. Para el autor, la búsqueda del andrógino es sinónimo de la búsqueda de la madre y del hijo perdidos, o lo que es lo mismo, la búsqueda de lo místico, del mundo de los orígenes, en la que sin embargo fracasará este personaje.

Paul, en cambio, logrará la conciliación entre los diferentes elementos del texto, a través de las tres etapas de su recorrido iniciático:

1.- El viaje a través del mundo, gracias al cual adquiere los conocimientos necesarios para acceder a la sublimación final.

2.- El rito de iniciación en sí mismo que consiste en hacer pasar a Paul por una prueba sumamente dolorosa. Esta es la muerte simbólica gracias a la cual podrá acceder al último paso dentro de la iniciación.

3.- Paul resucita simbólicamente y se convierte en meteoro. Al pasar a formar parte del cosmos se transforma en un ser aéreo. Adquiere un poder ilimitado porque adquire la inmortalidad, fundiendo de este modo espacio y tiempo, cosmos e Historia.

Puede decirse que Tournier es un escritor que intenta renovar algunos géneros literarios en desuso como son los géneros épicos, alegóricos y espirituales, a los que transmite nueva vida, insertando en ellos estructuras narrativas míticas en las que presenta a héroes que se dedican a la búsqueda de objetivos imposibles de alcanzar por un mortal, por lo que todos ellos se convierten en entes superiores e inmortales.

Tournier se vale de distintos mitos para relatar sus historias, sin embargo todas ellas presentan unos rasgos comunes: todos sus héroes corresponden a una concepción épica y se caracterizan por tener misiones totalmente irrealizables las cuales sólo ejecutan los seres sobrenaturales.

La personalidad de sus protagonistas es totalmente diferente en cada uno de sus textos, todos ellos viven aventuras esencialmente distintas. No obstante podemos decir que las vivencias de cada uno de ellos se asemejan bastante entre sí. El hilo conductor es el mismo: todos tienen un profundo deseo de trascendencia que se convierte en una lucha por la inmortalidad.

De esta forma, Abel y Paul, héroes principales de las obras analizadas, organizan toda su vida en relación a esa búsqueda de la trascendencia. La obtienen por muy diferentes caminos, sin embargo ambos llegan a lo mismo: la inmortalidad a través de algún elemento de la 
naturaleza. En el caso de Abel, gracias a la madre tierra y en el caso de Paul a través del espacio aéreo y por consecuencia del cosmos.

Los héroes de las dos novelas llevan a cabo un recorrido que corresponde a las distintas fases de los ritos iniciáticos y que culmina con la recuperación de una trascendencia perdida por el hombre en el curso de la Historia. 


\section{BIBLIOGRAFÍA}

Albouy, P. Mythes et mythologies dans la littérature française, Paris, A. Colin, 1969.

Altes, LK, "Un Mytique en trompe l'oeil: Le Roi des Aulnes de Michel Tournier" in Revue d'Histoires Littéraire de la France, vol 91, 4-5, 1991, pp.677-690.

Aziza, Claude; Olivieri, Claude y Sctrick, Robert. Dictionnaire des symboles et des thèmes littéraires, Ed. Fernand Nathan, 1978.

Bosquet, A. "Michel Tournier et les Mythes renouvelés" en La Nouvelle Revue Française 270, junio de 1972, pp.82-86.

Bouloumie, A. Michel Tournier. Le Roman Mythologique suivi des questions à Michel Tournier, Paris, José Corti, 1988.

Daly, MA. "Initiation and the Mythic Method in the Novel of Michel Tournier" in Dissertation Abstracts International, vol 41, 9, Mar, 1981, p. 4029A-4030A.

Durand, Gilbert. Structures Anthropologiques de l'Imaginaire, Paris, Bordas, 1969.

Easterlin, NL, "Iniciation and Counter-Initiation, Progress Toward Adulthood in the Stories of Tournier, Michael" in Studies in Short Fiction, Vol 28, 2, 1991, pp.151-168.

Eliade, Mircea. Iniciation, rites, sociétés secrètes, Paris, Gallimard, (Folio nº 196), 1959.

-Aspects du mythe, Paris, Gallimard (Folio n 100), 1963.

Jung, C.G. Arqutipos e Inconsciente Colectivo, Madrid, Ed. Paidos, 1981.

Levi-Strauss, C. Anthropologie Structurale, Paris, Bordas, 1969.

-Mito y Significado, Madrid, Alianza Editorial, 1987.

Tournier, Michel. Le Roi des Aulnes, Paris, Gallimard, 1970 (Folio ${ }^{\circ}$ 656).

-Les Météores, Paris, Gallimard, 1975 (F́lio nº 905).

Ugalde, JA, “La mitología de Michel Tournier” in Quimera: Revista de Literatura, vol 60, n.d., p.58-63. 